\title{
Analysis of fuel retention in plasma-facing components from controlled fusion devices
}

\author{
M. Rubel ${ }^{\text {a,* }}$, J.P. Coad ${ }^{\text {b }}$, J. Likonen ${ }^{\text {c }}$, V. Philipps ${ }^{\text {d }}$, JET-EFDA Contributors ${ }^{1}$ \\ a Alfvén Laboratory, School of Electrical Engineering, Royal Institute of Technology (KTH), Association Euratom - VR, 10044 Stockholm, Sweden \\ ${ }^{\mathrm{b}}$ Culham Science Centre, Euratom-UKAEA Fusion Association, Abingdon, UK \\ ${ }^{\mathrm{c}}$ VTT, Association Euratom-Tekes, 02044 VTT, Finland \\ d IEF-2, Forschungszentrum Jülich, Association Euratom-FZJ, Jülich, Germany
}

\section{A R T I C L E I N F O}

\section{Article history:}

Received 5 November 2008

Received in revised form 21 November 2008

Available online 7 December 2008

\section{PACS:}

52.40.Hf

\section{Keywords:}

Controlled thermonuclear fusion

Wall materials

Retention

Deuterium

Tokamak

\begin{abstract}
A B S T R A C T
First wall components in controlled fusion devices undergo severe modification by various physical and chemical processes arising from plasma-wall interactions: material erosion, its transport in the plasma and re-deposition. The intention of this work is to give a concise overview of key issues in the characterization of plasma-facing materials and components in tokamaks. The importance of surface analysis in studies of fuel inventory and material migration is presented. Experimental procedures and analysis methods are briefly reviewed with emphasis on ion beam techniques which play a prominent role in studies of wall components exposed to hot plasmas. Practical aspects in the analytical approach are addressed and special instrumentation used in these studies is described.
\end{abstract}

(C) 2008 EURATOM. Published by Elsevier B.V. All rights reserved.

\section{Introduction: plasma-material interactions and plasma- facing materials}

The main objective of this paper is to review the role of surface analysis in studies of plasma-material interactions (PMI) in magnetic devices for controlled thermonuclear fusion, such as tokamaks, where fusion reactions take place in a hot plasma confined by a magnetic field. The presentation is structured along three points. The introduction provides an explanation on "what" is to be analysed and "why", whereas following sections are focused on "how" the examination is carried out. The intention is to combine the information on crucial consequences of PMI with several aspects of the analysis of plasma-facing materials and components (PFM/C).

Two inter-related aspects in the operation of a fusion reactor safety and economy - are the driving forces for detailed studies of first wall components which undergo modification by particles escaping the plasma. These interactions comprise all processes involved in the exchange of mass and energy between the plasma

\footnotetext{
* Corresponding author. Tel./fax: +46 87906093.

E-mail address: rubel@kth.se (M. Rubel).

${ }^{1}$ See Appendix to paper: F. Romanelli et al., Fusion Energy 2008 (Proc 22nd Int. Conf. Geneva, Switzerland, 2008).
}

and the surrounding walls. Particles (ions, electrons, charge exchange neutrals) impacting on PFC cause physical sputtering, chemical erosion, melting, evaporation or sublimation [1-3]. Species removed from surfaces are ionized and then, are transported in the vessel along the magnetic field lines. Some fraction of the transported material is pumped out but the rest is re-deposited on surfaces in different location to the origin. Eroded atoms are re-deposited together with fuel species. This process, called codeposition, results in the formation of fuel-containing mixed material layers because in most fusion devices the edge plasma is in contact with more than one kind of material constituting the plasma-facing wall. The interior of controlled fusion devices has a complex structure, as presented in Fig. 1(a) and (b) which show the vacuum vessels of the TEXTOR and JET (Joint European Torus) tokamaks, respectively. TEXTOR is a medium size device (minor radius $0.52 \mathrm{~m}$ ) in Forschungszentrum Jülich, Germany. Limiters of various kinds (see Fig. 1(a)) are the high heat flux (HHF) components which "limit" the plasma and protect the Inconel ${ }^{\circledR}$ liner from the direct impact of particle fluxes. In JET (Fig. 1(b)), which is the largest existing tokamak at present, there are two categories of HHF components: limiters in the main chamber and a divertor in the bottom of the machine, where the greatest power loads are deposited. The divertor moves the location of intense plasma-wall interactions further away from the main chamber in order to 


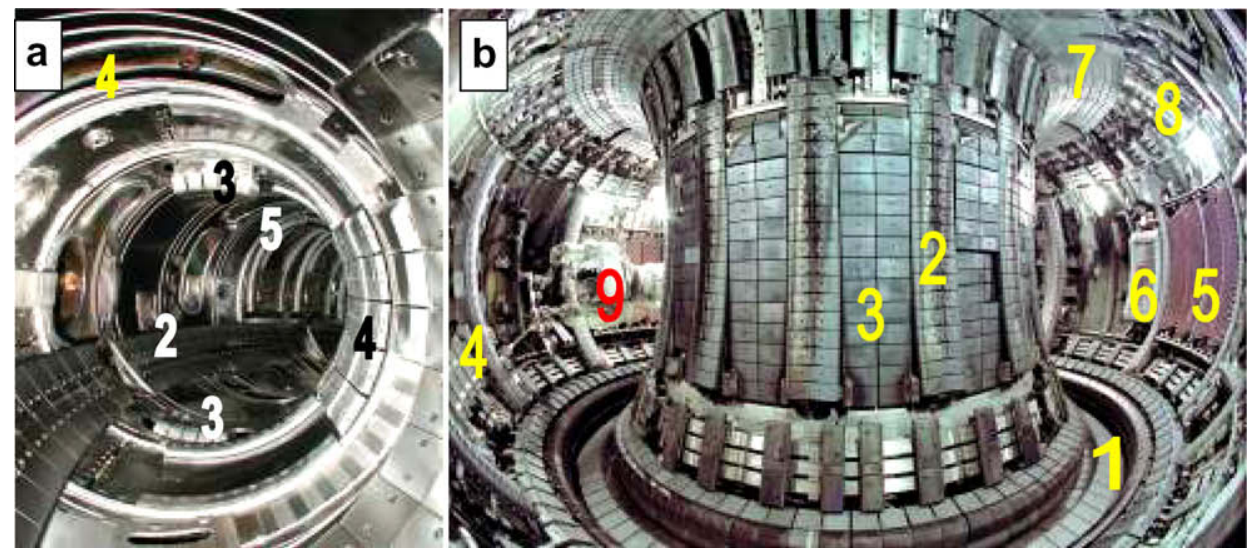

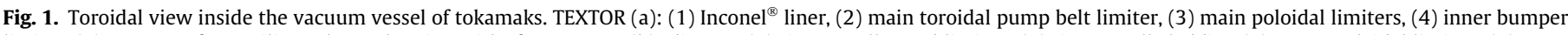

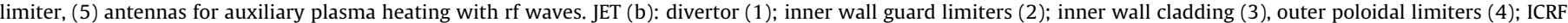

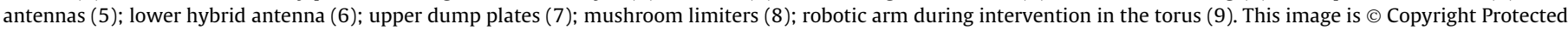
by EFDA JET.

prevent an excessive penetration of eroded particles into the discharge and thus to reduce the impact of impurities on the degradation of core plasma performance. In present-day machines the tiles of HHF components are mainly made with graphite and/or carbon fibre composites (CFC) because of excellent power handling capabilities and non-melting of carbon. However, chemical reactivity of carbon with hydrogen isotopes, used as fuel for fusion reactions, leads to the production of various hydrogenated species [1-6], i.e. $\mathrm{C}_{\mathrm{x}} \mathrm{I}_{\mathrm{y}}$, where I denotes fuel isotopes: hydrogen (H), deuterium (D) and tritium (T). This, in turn, results in the formation of hydrogenated co-deposited films of diverse thickness, structure, fuel content and mechanical properties [7-19]. The continuous growth of these co-deposited layers has strong implications for the operation of a future reactor because of tritium inventory and a potential source of dust in the case of disintegration of such films $[18,20]$. The present experience clearly shows that chemical erosion of carbon is the major mechanism responsible for fuel trapping by codeposition and long-term retention in fusion devices with carbon PFC [21-23]. As assessed after the full D-T operation in TFTR [21] and JET [22,23], this would lead to unacceptably high tritium retention in a power reactor $[1,24]$. As a consequence, frequent interruptions of machine operation would be needed to remove excessive amount of tritium from PFC. Moreover, the greatest deposition occurs in so-called remote areas shadowed from the direct plasma line-of-sight, e.g. entrance to pumping ducts difficult to reach by fuel removal methods $[23,25,26]$. Therefore, over the years, alternative materials for wall components have been extensively tested. In particular, metal walls are only physically sputtered by the plasma with low sputtering yield if incident ion energies are kept below a threshold value, and thus avoiding the contribution from chemical erosion specific to carbon. For instance, tungsten-coated graphite tiles have been tested in ASDEX-U on the main vessel wall and in the divertor [27-29], bulk tungsten test limiters in TEXTOR [30-35] and bulk molybdenum in Alcator CMod [36] and TEXTOR (test limiters) [37]. Beryllium (Be) has been used regularly in JET: evaporated Be layers on the main chamber wall and solid Be components (Faraday screens) of antennas for ion cyclotron resonance heating [38]. JET was also operated in the past with large-scale castellated beryllium structures: the toroidal belt limiter [39] and $\mathrm{Mk}-\mathrm{I}(\mathrm{Be})$ divertor tiles [11,40].

The ultimate goal of the PMI research program is the provision of best-possible solutions and predictions for the construction and operation of the next-step device: ITER - International Thermonuclear Experimental Reactor. The work includes the selection of wall materials, the assessment of in-vessel fuel and dust inventory as well as development of fuel and dust removal techniques. This requires detailed analysis of wall tiles and various probes retrieved from tokamaks. The importance of studies in existing tokamaks (operated in D-D or with a limited amount of $\mathrm{T}$ ) is related to the fact that the access to in-vessel components of a D-T reactor will be very limited.

Operational experience from present-day machines and results of a broad laboratory research programme have lead to the selection of three materials for different PFC during the first operation phase of ITER: beryllium (Be) for the main chamber wall, tungsten (W) for the dome and the upper part of the vertical divertor targets and CFC for the lower part of the divertors targets where the greatest power flux will be deposited [1]. The concept allows for minimizing the amount of carbon and, possibly, reducing the tritium inventory associated with chemical erosion. However, as long as the use of some carbon is considered, the study of its transport and impact on the inventory remains of critical importance.

Until now, neither these three materials nor even beryllium and tungsten have ever been tested together in any existing tokamak. For that reason the ITER-Like Wall Project (ILW) has been initiated at JET [41] in order to demonstrate the operation with beryllium on the main chamber wall and tungsten in the divertor (bulk metal for the load bearing plate and $\mathrm{W}$-coated CFC for other tiles). The other important issue to be addressed is fuel inventory in a metal-wall machine [41]. The project has also required an intense R\&D activity including a broad analysis programme in the material qualification process [41-43].

\section{Key issues and practical aspects in analysis of wall materials}

Key issues to be examined are the assessment of: (i) material erosion; (ii) accumulation of hydrogen isotopes in PFC; (iii) carbon and metal (Be and $\mathrm{W}$ ) dust formation. The research comprises three fundamental elements: (1) experiments in tokamaks and relevant PMI simulators, (2) ex-situ and in-situ analysis of wall components and (3) modeling work. Therefore, the analysis of wall materials is not an isolated activity but an integral part of the research program. Its main role is to help understand processes which modify materials and lead to the degradation of their properties and contamination of fusion plasmas by species eroded from the wall. The analysis must provide data for the assessment of erosion-deposition pattern in the entire vessel and, by this, for modeling of material transport. To tackle all points and to recognize material migration in a tokamak one applies a variety of 
techniques to perform relevant experiments and to accomplish broad examination of PFC. Experimental procedures include the implementation of erosion-deposition monitors (wall probes) installed in the vessel [47-50] and application of transport markers $[10,13,44-48]$. In the latter case, a trace amount of impurity is injected into the plasma and detected subsequently by post-mortem analysis of PFC.

Following the exposure to plasma, a number of wall tiles and all monitors are retrieved from the torus and transferred via air to the surface analysis station for ex-situ examination. In practice, the study is carried out with several limiters and at least one full poloidal section of divertor plates. Images in Fig. 2(a) and (b) show the appearance of PFC from TEXTOR, whereas tiles from different divertors used at JET are presented in Fig. 2(c-f). One may note shiny erosion zones (E) and areas covered by co-deposits (D) or even thick flaking layers. Scanning electron microscopy (SEM) image of the original graphite surface is in Fig. 3(a), whereas the plate structure in an erosion zone is presented in Fig. 3(b). The micrographs in Fig. 3(c)-(f) show different types of co-deposits.

The analysed tiles are of various shape, size and weight. Cutting these materials into smaller pieces is not a routine procedure $[23,47]$. It is avoided, whenever possible, because tiles are expensive and after cleaning they may be reused in a tokamak. This implies that the chambers of surface analysis stations must be large enough to accommodate such big specimens. They also have to be equipped with manipulators with a long linear travel distance and/or capable of handling and precise positioning of heavy specimens, e.g. bulk tungsten limiters tested in TEXTOR [32,51]. Special precautions are implemented when studying materials from JET which contain hazardous beryllium and tritium. Their presence necessitates using glove box isolators for handling and transfer of materials. It also requires isolated and tight ventilation and pumping systems, for details see [45].

The main species to be analysed are fuel isotopes ( $D$ and $T$ ) and constituents of major wall materials, i.e. carbon, beryllium and tungsten (and alloying additives). Other elements or particular isotopes are of interest if they were used as test components (e.g. Mo and various $\mathrm{C}-\mathrm{B}, \mathrm{C}-\mathrm{Si}, \mathrm{C}-\mathrm{Ti}$ composites) or for wall conditioning (e.g. boron, silicon, beryllium and lithium) and as markers for material transport studies (e.g. ${ }^{13} \mathrm{C}, \mathrm{Re}, \mathrm{Hf}$, etc.). The compounds formed as a result of material mixing on PFC under high temperature conditions are also to be determined.

Global characterization of surface changes caused by PMI is a mosaic work involving the application of over 30 different techniques [51]. They can be categorized along several lines, but the major issue is their effectiveness in quantitative, selective and sensitive determination of the content and distribution (lateral and indepth) of deuterium and several other species listed above. High
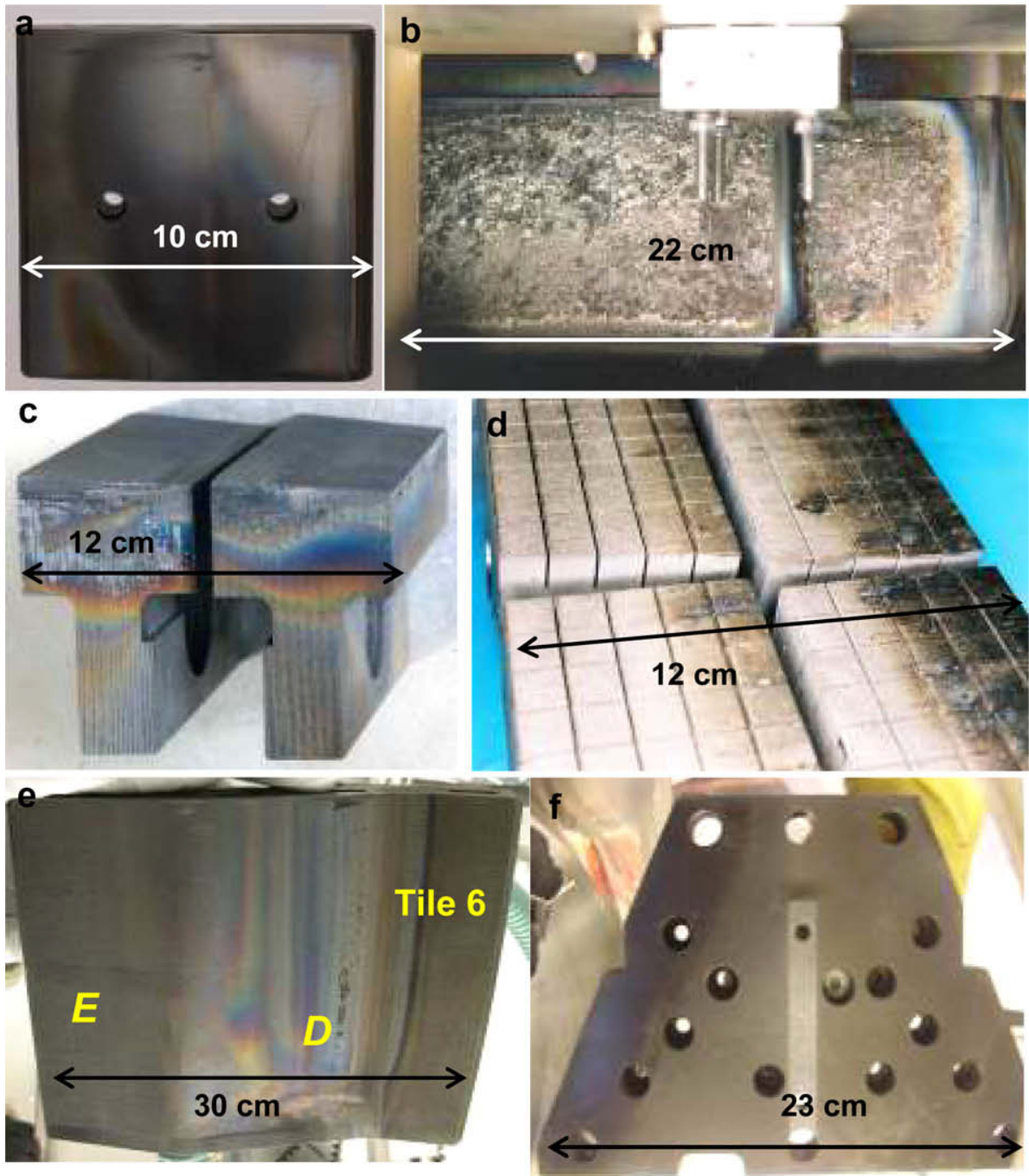

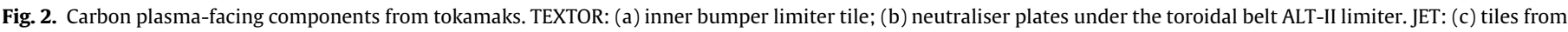
the Mk-I CFC divertor; (d) castellated tiles from the Mk-I Be divertor; (e) tile number 6 from the Mk-II Gas Box divertor and (f) support plate of the gas box structure. 

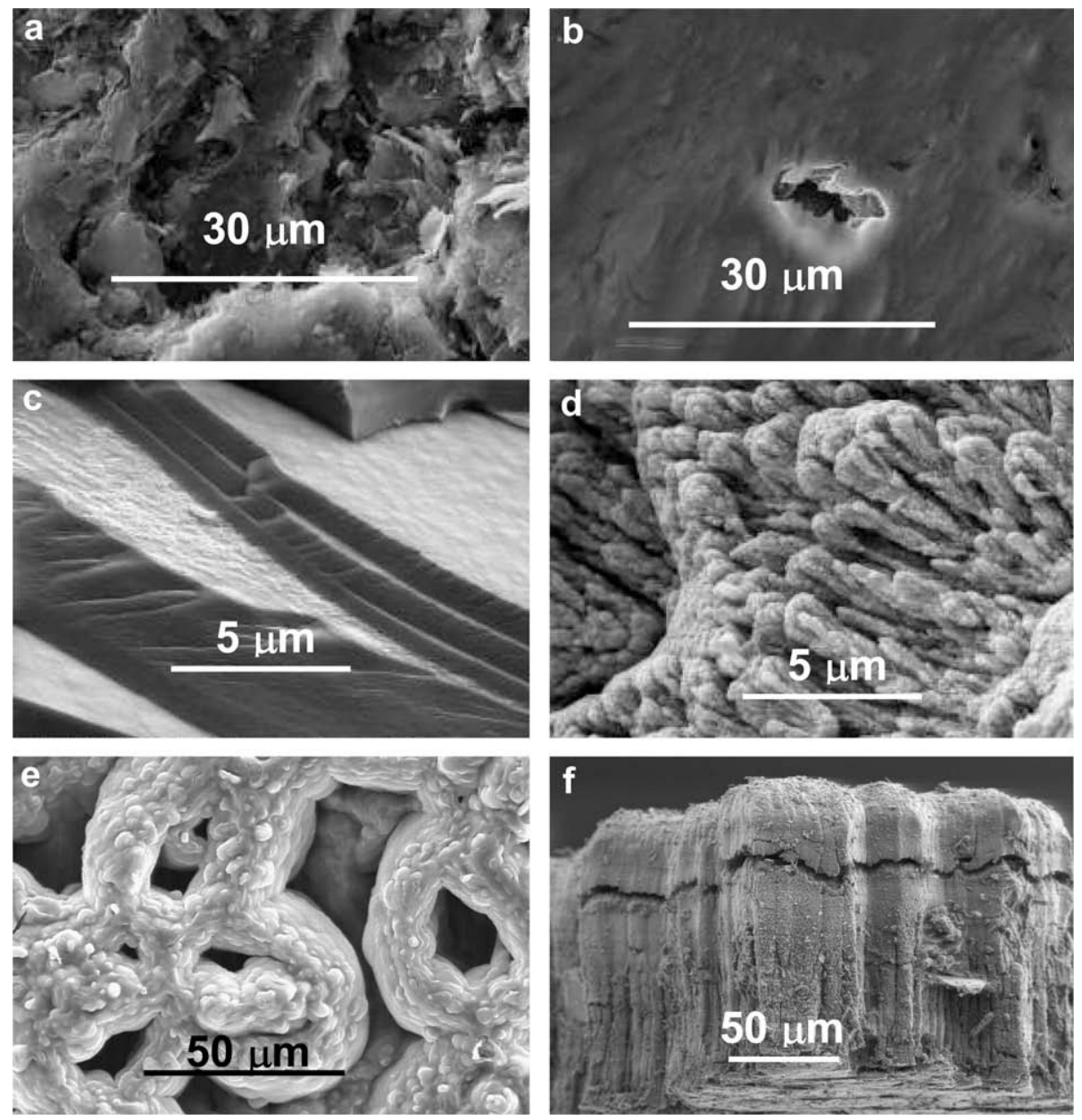

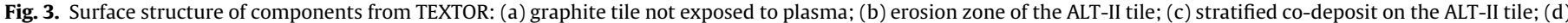
and (e) granular deposits on the neutraliser plates and rf-antenna protection tile, respectively; (f) columnar deposit on the main poloidal limiter.

speed in surveying many points over large areas is also important. Many of those criteria are met by accelerator-based ion beam analysis methods [51-55]. In most cases beams of light projectiles $\left(\mathrm{H}^{+}\right.$, ${ }^{3} \mathrm{He}^{+},{ }^{4} \mathrm{He}^{+}$) are used for nuclear reaction analysis (NRA), elastic recoil detection analysis (ERDA), enhanced proton scattering (EPS) and Rutherford back-scattering spectroscopy (RBS). The most powerful tool is NRA with a ${ }^{3} \mathrm{He}^{+}$beam as it offers a broad range of analysis because of the high nuclear reactivity of that helium isotope. Fig. 4 shows a spectrum recorded with a $2.5 \mathrm{MeV}^{3} \mathrm{He}^{+}$beam for a divertor tile from JET after experiments with ${ }^{13} \mathrm{CH}_{4}$ used as a marker of carbon migration studies [45-48]. There is a clear sepa-

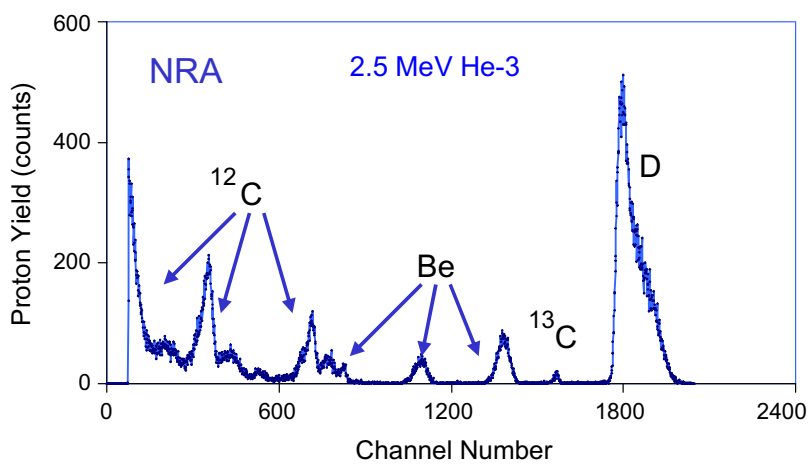

Fig. 4. NRA spectrum for a co-deposit on a divertor tile from JET recorded after experiments with $\mathrm{C}-13$ marker of carbon transport. ration of peaks associated with protons originating from ${ }^{12} \mathrm{C},{ }^{13} \mathrm{C}$, Be and D via the nuclear reactions: ${ }^{12} \mathrm{C}\left({ }^{3} \mathrm{He}, \mathrm{p}\right){ }^{14} \mathrm{~N},{ }^{13} \mathrm{C}\left({ }^{3} \mathrm{He}, \mathrm{p}\right){ }^{15} \mathrm{~N}$, $\mathrm{d}\left({ }^{3} \mathrm{He}, \mathrm{p}\right) \alpha,{ }^{9} \mathrm{Be}\left({ }^{3} \mathrm{He}, \mathrm{p}\right){ }^{11} \mathrm{~B}$. Analysis conditions of reactor materials with IBA have been summarized in [51]. However, all methods (including IBA) have inherent limitations. In solving a given problem one has to select and apply the most appropriate set of complementary techniques. Some examples will be given in the following section focused on the fuel retention issue.

\section{Application of surface analysis to fuel retention studies}

Fig. 5(a) shows a tile from the toroidal belt limiter (ALT-II, Advanced Limiter Test) retrieved from TEXTOR after over 14,000 s of plasma operation. Two regions can be distinguished: a smooth erosion zone and a deposition zone with a thick co-deposited layer which detaches and peels-off, thus forming dust $[8,17,18]$. The amount and distribution of deuterium along the poloidal direction on two such tiles is plotted in Fig. 5(b) whereas a graph in Fig. 6 shows NRA deuterium depth profile in the layer. The proton yield from the $d\left({ }^{3} \mathrm{He}, \mathrm{p}\right) \alpha$ nuclear reaction can be converted to the deuterium content in the analysed film. One may notice a somewhat non-uniform deuterium distribution which is related to the stratified structure of co-deposits containing also boron-rich layers originating from regular wall conditioning of TEXTOR by boronisation [7,13]; the stratified deposit is shown in Fig. 3(c).

However, before extrapolating to a global D inventory from these measurements, a first problem to be solved is the thickness 
a

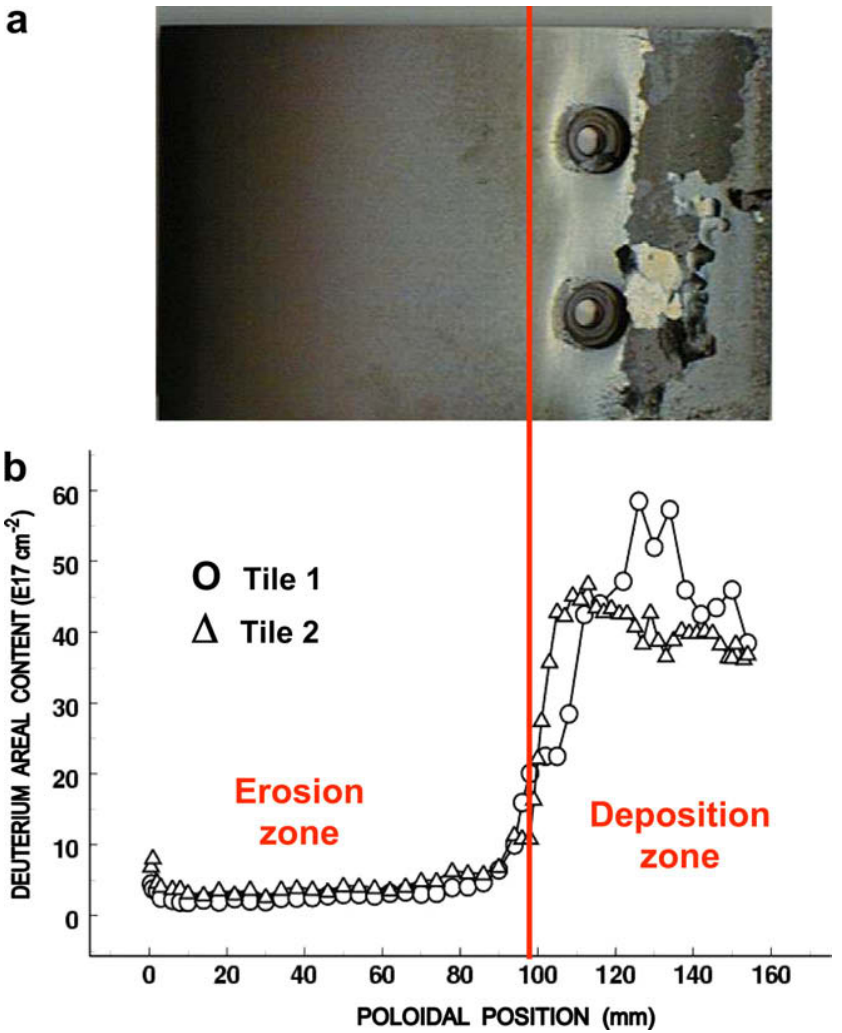

Fig. 5. (a) Exposed ALT-II limiter tile from TEXTOR and (b) deuterium distribution determined with NRA on the surface of two different tiles.

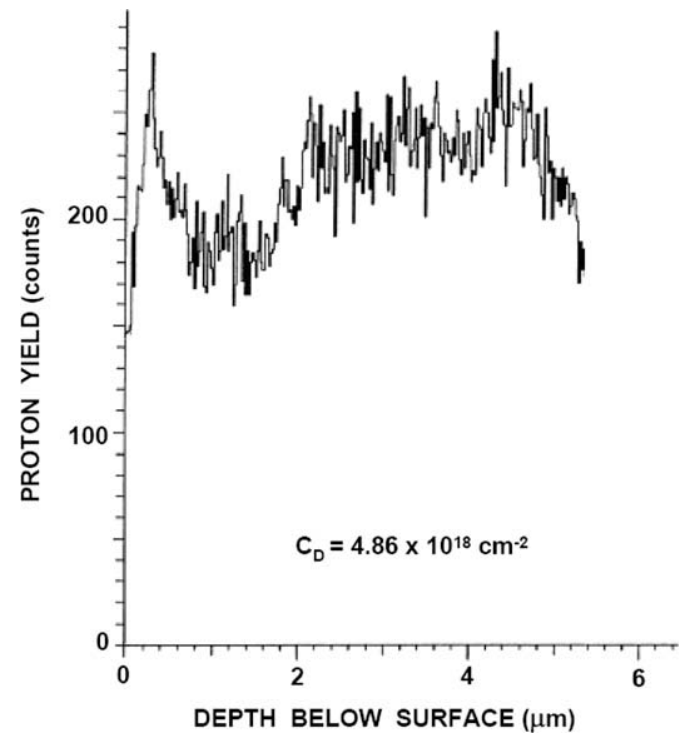

Fig. 6. Deuterium depth profile in the deposition zone on the ALT-II limiter tile from TEXTOR. The proton yield from the $\mathrm{d}\left({ }^{3} \mathrm{He}, \mathrm{p}\right) \alpha$ nuclear reaction is converted to the deuterium content in the analysed film.

of the deposited layer. Indeed, the measurements have been done by means of NRA using a $1.5 \mathrm{MeV}^{3} \mathrm{He}^{+}$beam and detecting protons emerging from the $d\left({ }^{3} \mathrm{He}, \mathrm{p}\right) \boldsymbol{\alpha}$ reaction. Under these conditions the information depth in the carbon matrix is limited to around $4.5 \mu \mathrm{m}$, whereas the entire layer thickness has been greater as checked by increasing the ${ }^{3} \mathrm{He}^{+}$beam energy, thus increasing the information depth. However, even with a $3 \mathrm{MeV}$ beam, the corresponding information depth in carbon layers does not exceed
$10 \mu \mathrm{m}$ while the total thickness of co-deposits on ALT-II has been around $45 \mu \mathrm{m}$ as measured by SEM on the detached flakes [8]. Higher beam energies (up to $6 \mathrm{MeV}$ ) have been used to scan the deuterium content even deeper in samples [56]. If a deposit is detached, the thickness of the layer can be measured directly with microscopy and the D content measured with NRA from both sides of a detached flake. In the case of well adhering co-deposited layers one applies secondary ion mass spectroscopy (SIMS) to determine the layer thickness and uniformity of deuterium distribution. By combining NRA measurements with an independent determination of the layer thickness (i.e. using SIMS or SEM), the distribution and content of deuterium on the entire plate can be assessed. Another method used to determine the total amount of fuel in PFC (but no information on the local D distribution within the sample) is thermal desorption spectroscopy (TDS), where the whole tile is heated up and the outgassed species are analysed. The results of surface studies and TDS have agreed within $10 \%$ : e.g. $1 \times 10^{21}$ and $1.1 \times 10^{21} \mathrm{D}$ atoms per ALT-II tile, respectively [7]. This allowed the total deuterium content in all plates of the ALT-II belt limiter at TEXTOR to be assessed as $2.3 \times 10^{23} \mathrm{D}$ atoms. As a result of studies done for all types of in-vessel components of TEXTOR (various limiters, liner, neutralizer plates, etc.) the areas of the greatest co-deposition have been identified and total fuel inventory could be assessed. Similar type of studies have recently been undertaken in Tore Supra to resolve the issue of long-term retention in that tokamak $[14,57]$.

In the case of complex thick co-deposits, such as formed in JET on the divertor plates, SIMS is the most efficient method to determine the layer thickness and depth distribution of species [46]. Fig. 7 shows depth profiles of deuterium, beryllium, carbon isotopes and nickel on the inner target (Tile 3) of the MK-II Gas Box divertor. The tile was analysed after the experiment with ${ }^{13} \mathrm{C}$ tracer injection performed on the last operation day with that divertor, i.e. just before the major shut-down and retrieval of tiles $[46,47]$. One notes distinct peaking of ${ }^{13} \mathrm{C}$ deposited on the surface during that experiment. The outer layer (up to approx. $15 \mu \mathrm{m}$ ) contains mostly ${ }^{12} \mathrm{C}$ and Be together with deuterium, but the composition deeper into the deposit is quite different to the surface composition. It shows that the majority of the film $(15-32 \mu \mathrm{m})$ is very rich in beryllium, and nickel also peaks in this region due to chemical sputtering of $C$ from the film. However, the outer layer is associated with a period of JET operation with ${ }^{4} \mathrm{He}$ plasmas during which time chemical sputtering was reduced. In this sense, SIMS allows for detailed studies of tile history. However, direct quantification of species meets difficulties because of matrix effects and, as determined by RBS, the presence of oxygen which increases the secondary ion yield and signal intensity [58,59].

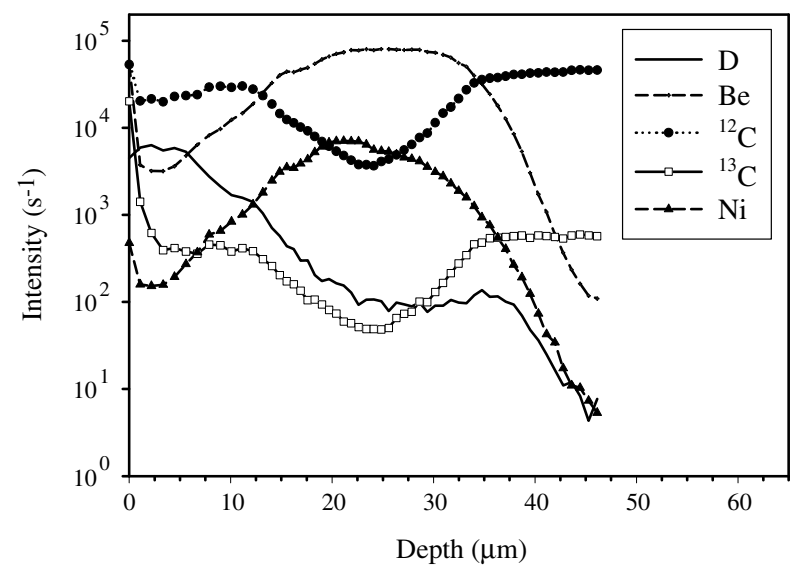

Fig. 7. SIMS depth profile of deuterium, beryllium, carbon and nickel in the central part of Tile 3 from the Mk-II Gas Box divertor at JET 
Another major problem in quantification of hydrogen isotopes with NRA is ion-induced detrapping of species [60-62] by the high energy analysing beam. Therefore, the analysis of deuterium should be performed with a relatively small ${ }^{3} \mathrm{He}^{+}$dose (not exceeding $1 \mu \mathrm{C})$, unless it is the detrapping process itself being studied $[60,62]$. The effective cross-sections for detrapping depend on the layer structure and its chemical composition, i.e. hybridisation, content of various plasma impurities in co-deposits, etc. The substrate temperature during the layer formation also plays a role. Plots in Fig. 8 show the change in deuterium depth profile and content in a co-deposit irradiated with an increasing dose of $1.5 \mathrm{MeV}^{3} \mathrm{He}^{+}$beam: $4.68 \times 10^{14}(\mathrm{~A}), 23.4 \times 10^{15}$ (B) and $46.8 \times$ $10^{15}$ ions $\mathrm{cm}^{-2}(\mathrm{C})$. They are recorded for a co-deposit formed on a collector probe exposed to the edge plasma at TEXTOR during discharges heated by neutral beam injection (NBI). The depth profiles prove a gradual but substantial release of deuterium under the helium bombardment. Prolonged irradiation reduces the concentration from $2.57 \times 10^{18} \mathrm{~cm}^{-2}$ to $1.4 \times 10^{18} \mathrm{~cm}^{-2}$ corresponding to the release of at least $46 \%$ of deuterium. However, the concentration drop is not homogeneous throughout the layer. In the near surface region the concentration remains nearly unaffected whereas the released amount increases with depth: $51 \%$ is released from the deepest region of the deposit; $34 \%$ from the middle layer $(0.5-1.5 \mu \mathrm{m})$ and only few per cent from the surface region. This detrapping characteristic may be attributed to several factors related both to the nature of the detrapping process itself and to the nature of hydrogenated co-deposits containing different $\mathrm{C}-\mathrm{H}$ binding states. The detrapping of deuterium by $\mathrm{MeV}$ He ions occurs mostly via electronic excitations [63] and the effect is pronounced at a greater depth, where the ion energy is deposited most effectively. The electronic stopping power of $1.5 \mathrm{MeV}^{3} \mathrm{He}$ ions in carbon increases with depth reaching its maximum between 3 and $4 \mu \mathrm{m}$, i.e. in the region where the most effective detrapping has occurred. Secondly, hydrogenated carbon films retain deuterium in states of different binding energy $[64,65]$. Loosely bound states are easily decomposed. It may additionally explain the fact that relatively more deuterium is released, and more easily, from the depth of the deposit than from the surface layer containing small amounts of $\mathrm{D}$. The surface layer is probably less abundant in low energy binding states because of the thermal effects, as mentioned above.

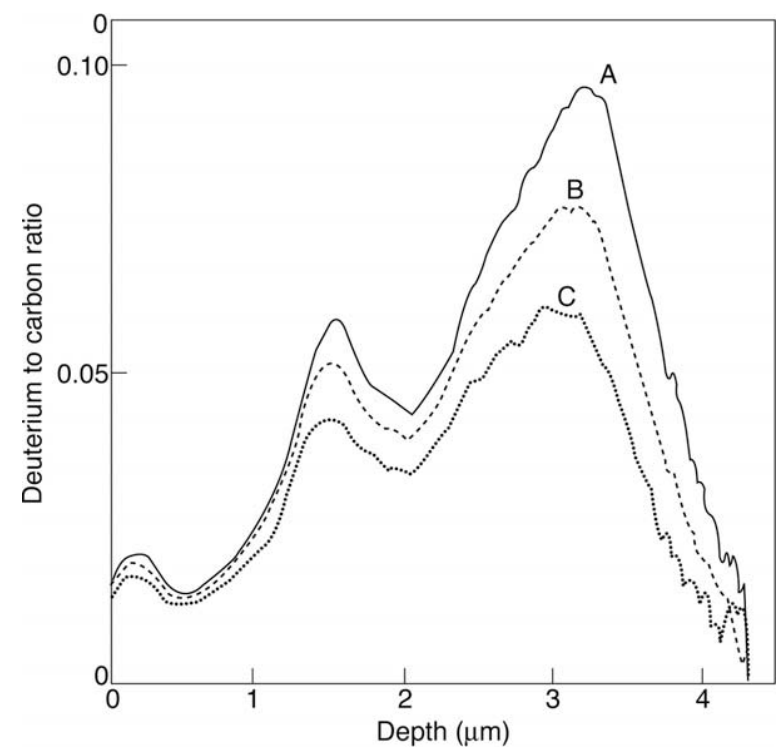

Fig. 8. The change in deuterium depth profiles following the irradiation of a codeposit with an increasing dose of $1.5 \mathrm{MeV}^{3} \mathrm{He}^{+}: 4.68 \times 10^{14}$ (A), $23.4 \times 10^{15}$ (B) and $46.8 \times 10^{15}$ ions $\mathrm{cm}^{-2}(\mathrm{C})$.
The rise of the probe temperature by a few hundred degrees during NBI pulses was measured during the last phase of the experiment. The impact of tile temperature on the characteristic of ion-induced detrapping has also been observed for co-deposits formed in different regions on the limiters and divertor plates at JET [26]. Up to $60 \%$ of deuterium could be removed from so-called "soft" amorphous carbon films formed in the shadowed region of the inner divertor, whereas less than $5 \%$ was detrapped from hot surfaces of inner wall guard limiters. Very strong ion-induced effects are observed when analysing hydrogen with a $6 \mathrm{MeV}{ }^{15} \mathrm{~N}$ beam $\left[\mathrm{p}\left({ }^{15} \mathrm{~N}, \alpha\right){ }^{12} \mathrm{C}\right]$, because of large energy deposition in a shallow subsurface layer.

Another source of uncertainty in quantification of deuterium is related to immediate desorption of loosely bound deuterium and possible isotope exchange with hydrogen via water vapour when specimens are in contact with air during the transportation from the tokamak vessel to the surface analysis station. Rapid release of $\mathrm{D}$ and $\mathrm{T}$ (as deuterated and tritiated water) when venting JET has been observed [66]. However, it is very difficult to assess the extent of $\mathrm{D}$ release because for practical reason the surface analysis cannot be performed immediately after venting of a tokamak.

IBA techniques are seldom used for studies of radioactive tritium because of serious practical difficulties. The reaction with helium-3 $\left[{ }^{3} \mathrm{He}(\mathrm{t}, \mathrm{d})^{4} \mathrm{He}\right]$ gives a very broad peak, whereas the application of a deuterium beam (e.g. $[t(d, \alpha) n])$ requires a robust shield of the laboratory because of neutron production. Accelerator mass spectrometry (AMS) [67] has been applied for simultaneous depth profiling of H, D and T in samples from the JET [68]. A limiting factor is the cost of equipment necessary for AMS. On some occasions neutron-based ERDA has been applied but lateral resolution has not been satisfactory [69].

Investigation of the isotope distribution in the surface region can be accomplished by means of tritium imaging plate technique (TIPT) $[70,71]$ and/or Beta $(\beta)$ induced X-ray spectroscopy (BIXS) [72]. The information depth is limited to approximately $5 \mu \mathrm{m}$. A plate is exposed directly to the surface of a PFC tile in a shielded dark room and then processed by a digitised intensity reader. In some cases the technique allows discrimination between codeposited and deeply implanted non-confined tritium from the $\mathrm{D}-\mathrm{D}$ fusion. A germanium detector is used in BIXS to record Xray spectra induced by $\beta$-rays. The detector is placed near the examined sample (around $5 \mathrm{~mm}$ ) and the space between them is filled with flowing argon. The major advantage of TIPT and BIXS is mapping of tritium over large areas.

Mapping with TIPT has been done for tiles from JET after the full D-T campaign [71], whilst the analysis of the total T content in these tiles has been accomplished at the Tritium Laboratory at the Forschungszentrum Karlsruhe. Limiter and divertor tiles were sectioned first by coring technique and then by slicing the cylindrical samples into $1 \mathrm{~mm}$ thick discs which were then fully combusted in oxygen thus transforming tritium into tritiated water. The amount of tritium was then determined by liquid scintillography, for details see [23].

\section{Concluding remarks}

Key issues in the application of surface analysis for studies of fuel retention in wall materials of fusion devices have been presented. The analysis is crucial to answer questions: what has happened and why has it happened? This, in turn, enhances understanding of co-deposition in tokamaks and creates grounds for developing tools and methods for fuel removal [73-77].

The variety of materials to be examined and the complexity of analytical approach is broad. Due to the underlying physics all methods have their inherent advantages and limitations: sensitiv- 
ity, range of detected elements, information depth, resolution. Each method delivers only a certain type of information, hence there is no universal set of techniques serving all needs. Instead, solving a given problem requires a selection and application of an appropriate set of complementary techniques. In summary, the combination of several methods for fuel analysis in materials from different parts of the machine allow for the estimation of a total long-term fuel inventory. As a further step, the results of ex-situ studies should be compared with gas balance measurements in order to obtain the full picture and to understand the dynamics of fuel retention in a tokamak $[78,79]$.

\section{Acknowledgements}

This work, supported by the European Communities under the contract of Association between EURATOM/VR, was carried out within the framework of the European Fusion Development Agreement. The views and opinions expressed herein do not necessarily reflect those of the European Commission. The work was partly carried out under the Contract 2006-3271 from the Swedish Research Council.

\section{References}

[1] G. Federici et al., Nucl. Fusion 41 (2001) 697.

[2] V. Philipps, A. Kirschner, P. Wienhold, M. Rubel, Vacuum 67 (2002) 399.

[3] J. Roth, E. Tsitrone, A. Loarte, Nucl. Instr. and Meth. B 258 (2007) 253.

[4] E. Vietzke et al., J. Nucl. Mater. 145-147 (1987) 443.

[5] A. Mech, A.A. Haasz, J.W. Davis, J. Nucl. Mater. 255 (1998) 153.

[6] J. Roth, J. Nucl. Mater. 266-269 (1999) 51.

[7] M. Rubel et al., J. Nucl. Mater. 290-293 (2001) 473.

[8] M. Rubel et al., Phys. Scr. T 103 (2003) 20.

[9] R. Behrisch et al., J. Nucl. Mater. 145-147 (1987) 723.

[10] J.P. Coad et al., J. Nucl. Mater. 313-316 (2003) 419.

11] J.P. Coad, M. Rubel, C.H. Wu, J. Nucl. Mater. 241-243 (1997) 408.

[12] V. Rohde, M. Mayer, ASDEX-U Team, Phys. Scr. T 103 (2003) 25

[13] P. Wienhold et al., J. Nucl. Mater. 313-316 (2003) 311.

[14] B. Pegourie et al., Overview of deuterium inventory in Tore Supra: operational conditions and particle balance, 18th Int. Conf. on Plasma-Surface Interactions, Toledo, Spain, May 2008, J. Nucl. Mater., in press.

[15] Y. Gotoh et al., J. Nucl. Mater. 329-333 (2004) 840.

[16] C.H. Skinner et al., Nucl. Fusion 39 (1999) 1081.

[17] J. Linke et al., Phys. Scr. T 91 (2001) 36.

[18] M. Rubel et al., Nucl. Fusion 41 (2001) 1087.

[19] J. Likonen et al., J. Nucl. Mater. 363-365 (2007) 190.

[20] J. Roth et al., in: 22nd IAEA Conference on Fusion Energy, Geneva, Switzerland, October 2008

[21] C.H. Skinner et al., J. Nucl. Mater. 266-269 (1999) 940.

[22] P. Andrew et al., Fusion Eng. Des. 47 (1999) 233.

[23] R.D. Penzhorn et al., J. Nucl. Mater. 288 (2001) 170.

[24] J. Roth et al., Recent analysis of key plasma-wall interaction issues in ITER, 18th Int. Conf. on Plasma-Surface Interactions, Toledo, Spain, May 2008, J Nucl. Mater., in press.

[25] J.P. Coad et al., J. Nucl. Mater. 290-293 (2001) 224.

[26] M. Rubel et al., J. Nucl. Mater. 313-316 (2003) 321.

[27] R. Neu et al., J. Nucl. Mater. 313-316 (2003) 116.
[28] K. Krieger et al., J. Nucl. Mater. 337-339 (2005) 10.

[29] R. Dux et al., Plasma-wall interactions and plasma behaviour in the nonboronised all tungsten ASDEX Upgrade, 18th Int. Conf. on Plasma-Surface Interactions, Toledo, Spain, May 2008, J. Nucl. Mater., in press.

[30] V. Philipps et al., J. Nucl. Mater. 258-263 (1998) 858.

[31] A. Pospieszczyk et al., J. Nucl. Mater. 290-293 (2001) 947.

[32] M. Rubel, V. Philipps, A. Huber, T. Tanabe, Phys. Scr. T 81 (1999) 61

[33] T. Hirai et al., J. Nucl. Mater. 313-316 (2003) 67.

[34] T. Hirai et al., Phys. Scr. T 103 (2003) 59.

[35] V. Philipps et al., Plasma Phys. Control Fusion 42 (2001) B 293.

[36] W.R. Wampler et al., J. Nucl. Mater. 266-269 (1999) 217.

[37] V. Philipps et al., Nucl. Fusion 34 (1994) 1417.

[38] P. Thomas et al., J. Nucl. Mater. 176-177 (1990) 3.

[39] M. Rubel, J.P. Coad, D. Hole, Overview of long-term fuel inventory and codeposition in castellated beryllium limiters at JET, J. Nucl. Mater., in press.

[40] M. Rubel, J.P. Coad, R.A. Pitts, J. Nucl. Mater. 367-370 (2007) 1432.

[41] G.F. Matthews et al., Phys. Scr. T 128 (2007) 137.

[42] T. Hirai et al., Fusion Eng. Des. 82 (2007) 1839.

[43] H. Maier et al., Nucl. Fusion 47 (2007) 222.

[44] P. Wienhold et al., J. Nucl. Mater. 290-293 (2001) 362.

[45] M. Rubel, J.P. Coad, D. Hole, Vacuum 78 (2005) 255

[46] J.P. Coad et al., Nucl. Fusion 46 (2006) 350.

[47] J. Likonen et al., Fusion Eng. Des. 66-68 (2003) 219.

[48] M. Rubel et al., J. Nucl. Mater. 329-333 (2004) 795.

[49] M. Mayer et al., Phys. Scr. T 81 (1999) 13.

[50] J.P. Coad et al., Fusion Eng. Des. 74 (2005) 745

[51] M. Rubel, Phys. Scr. T 123 (2006) 54.

[52] J.W. Mayer, E. Rimini, Ion Beam Handbook for Material Analysis, Academic Press, New York, 1977.

[53] W.K. Chu, M. Mayer, M.A. Nicolet, Backscattering Spectroscopy, Academic Press, New York, 1978.

[54] J.F. Ziegler, Ion Beam Analysis, North Holland, 1990.

[55] J.R. Tesmer, M. Nastasi (Eds.), Handbook of Modern Ion Beam Analysis, Materials Research Society, Pittsburg, USA, 1995.

[56] M. Mayer et al., Quantitative depth profiling of deuterium up to very large depths, Nucl. Instr. and Meth. B, doi:10.1016/j.nimb.2008.11.033.

[57] E. Tsitrone et al., Deuterium retention in Tore Supra long discharges, in: 20th IAEA Conference on Fusion Energy, Villamoura, Portugal, November 2004.

[58] A. Bonninghoven, L. Wiedmann, Surf. Sci. 41 (1974) 79.

[59] A. Müller, A. Bonninghoven, Surf. Sci. 41 (1974) 483.

[60] J. Roth et al., J. Nucl. Mater. 93-94 (1980) 601.

[61] K. Morita, Y. Hasebe, J. Nucl. Mater. 176-177 (1990) 213.

[62] M. Rubel, H. Bergsåker, P. Wienhold, J. Nucl. Mater. 241-243 (1997) 1026.

[63] H. Bergsåker, S. Nagata, M. Rubel, B. Emmoth, Proc. Symp. Amorphous Hydrogenated Carbon Films, E-MRS 17 (1987) 433.

[64] R. Causey, M.I. Baskes, K.L. Wilson, J. Vac. Sci. Technol. A 4 (1986) 1189.

[65] W. Jacob, Thin Solid Films 326 (1998) 1.

[66] J.P. Coad et al., J. Nucl. Mater. 160 (1988) 95

[67] R. Hellborg et al., Vacuum 70 (2003) 365.

[68] M. Friedrich et al., Phys. Scr. T 94 (2001) 98.

[69] B.G. Skorodumov et al., Nucl. Instr. and Meth. B 85 (1994) 803.

[70] T. Tanabe, K. Miyasaka, M. Rubel, V. Philipps, Fusion Sci. Technol. 41 (2002) 924.

[71] T. Tanabe et al., J. Nucl. Mater. 313-316 (2003) 478.

[72] M. Matsuyama et al., J. Nucl. Mater. 313-316 (2003) 437.

[73] A. Widdowson et al., J. Nucl. Mater. 363-365 (2007) 341.

[74] C. Grisolia et al., Fusion Eng. Des. 82 (2007) 2390.

[75] G. Counsell et al., Plasma Phys. Control Fusion 48 (2006) B189.

[76] M. Rubel et al., J. Nucl. Mater. 363-365 (2007) 877.

[77] C. Hopf et al., J. Nucl. Mater. 363-365 (2007) 882.

[78] M. Mayer et al., J. Nucl. Mater. 290-293 (2001) 381.

[79] T. Loarer et al., Fuel retention in tokamaks, 18th Int. Conf. on Plasma-Surface Interactions, Toledo, Spain, May 2008, J. Nucl. Mater., in press. 